\title{
МОРФОЛОГИЧЕСКИЙ АНАЛИЗ В ИНДИВИДУАЛЬНОЙ ПРОЕКТНОЙ ДЕЯТЕЛЬНОСТИ ПО МАТЕМАТИКЕ
}

\author{
Кучерова Наталья Александровна \\ преподаватель общеобразовательной \\ дисциплины «Математика» \\ ГБПОУ ВО «Воронежский государственный \\ профессионально-педагогический колледж»
}

Аннотация: В статье рассматриваются методы обработки информации и генерации творческих идей в организации проектно-исследовательской деятельности обучающихся. Приведен пример применения математических методов в конструировании одежды.

Ключевые слова: проект, проектно- исследовательская деятельность, ментальная карта, морфологический анализ, творческое воображение.

\section{MORPHOLOGICAL ANALYSIS IN INDIVIDUAL PROJECT ACTIVITY IN MATHEMATICS}

\section{Kucherova Natalia Aleksandrovna}

\begin{abstract}
The article discusses the methods of information processing and generation of creative ideas in the organization of design and research activities of students. An example of the application of mathematical methods in the design of clothing is given.
\end{abstract}

Key words: project, design and research activity, mental map, morphological analysis, creative imagination.

Темпы развития современной цивилизации очень высоки. Человечеству приходиться за единицу времени обрабатывать гигабайты информации, решать большое количество проблемных задач, а это есть творчество, потому что при их решении создаются новые материальные и духовные ценности. Тогда 
современному обществу требуется все больше творческих личностей. Если в начале XX века считали, что творчество, это удел не многих, а только тех, кого наделила природа, то в цифровом обществе творческие способности необходимы каждому и развивают их уже с дошкольного возраста. Такая ситуация предполагает существенные изменения в образовании, что ведет к появлению инноваций по совершенствованию репродуктивных методов обучения. Разработанный еще в первой половине XX века метод проектов, который часто называют методом проблем, вновь становится актуальным в современном информационном обществе. Проектная деятельность, направлена на решение интересной проблемы, позволяет обучающимся проявить себя индивидуально или в группе, попробовать свои силы, приложить свои знания, принести пользу, показать публично достигнутый результат [1, с. 1].

Сюжеты проблемных задач повсюду, возьмем те, которые связаны с будущей профессиональной деятельностью обучающихся. Для их решения необходимы знания не только учебных, профессиональных дисциплин и модулей, но логическая система методов и приемов развития творческого воображения, таких как: мозговой штурм, метод каталога, системный оператор, инверсия, метод золотой рыбки, снежный ком, моделирование маленькими человечками. Многие из них идеально вписываются в учебный процесс, а так же в различные этапы работы над проектом, легки в применении, как для групповой работы, так и для индивидуальной работы, относятся к активным и интерактивным методам обучения. Например, метод морфологического анализа (ММА), основоположником которого считается швейцарский ученый Фриц Цвикки, астроном с мировым именем, автор теории о существовании нейтронных звезд, перенес метод построения многомерных таблиц на технику и получил большое число оригинальных технических объектов [3, с. 191].

Для успешного продолжения образования по специальности «Конструирование, моделирование и технология швейных изделий» программой по математике предусмотрено ее изучение, связанное с прикладным использованием в будущей профессии. Потому как на рынке труда востребованы не сами по себе знания, а способность специалиста применять их на практике, выполнять определенные профессиональные и социальные 
функции. Поэтому использование ММА в проектной работе «Разработка коллекции элементов пляжной одежды без швов с использованием поверхностей многогранников и тел вращения» в рамках изучения тем «Многогранники» и «Тела вращения», является универсальным средством для будущего конструктора-модельера, его применение в дальнейшей профессиональной деятельности на любом этапе технологического процесса приведет к высоким результатам.

Многогранники образуют в пространстве развертываемые поверхности, а одежда, обувь и перчатки имеют сложную пространственную форму, которая не может быть описана простой математической зависимостью, их поверхность не развертываемая.

Целью нашей проектной работы является разработка одежды без швов, в конструкции которой будут использованы различные фигуры и поверхности геометрических тел, следовательно, поверхность ее будет развертываемой. На первом этапе разработки проектного продукта проводится малыми группами морфологический анализ, имеющихся на интернет пространстве моделей и заполняется матрица при выбранных параметрах. Заполненную таблицу, обучающиеся, дорабатывают именно своими конструкциями изделий.
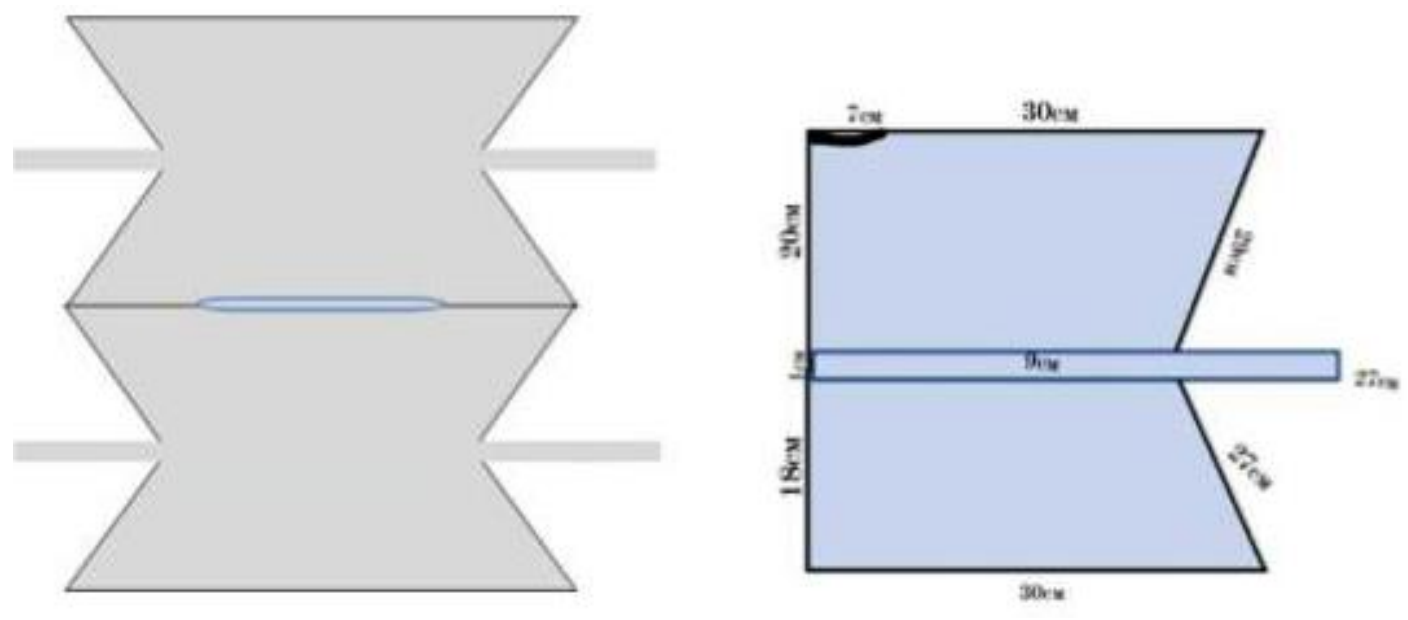

Рис. 1. Конструкция авторской модели 


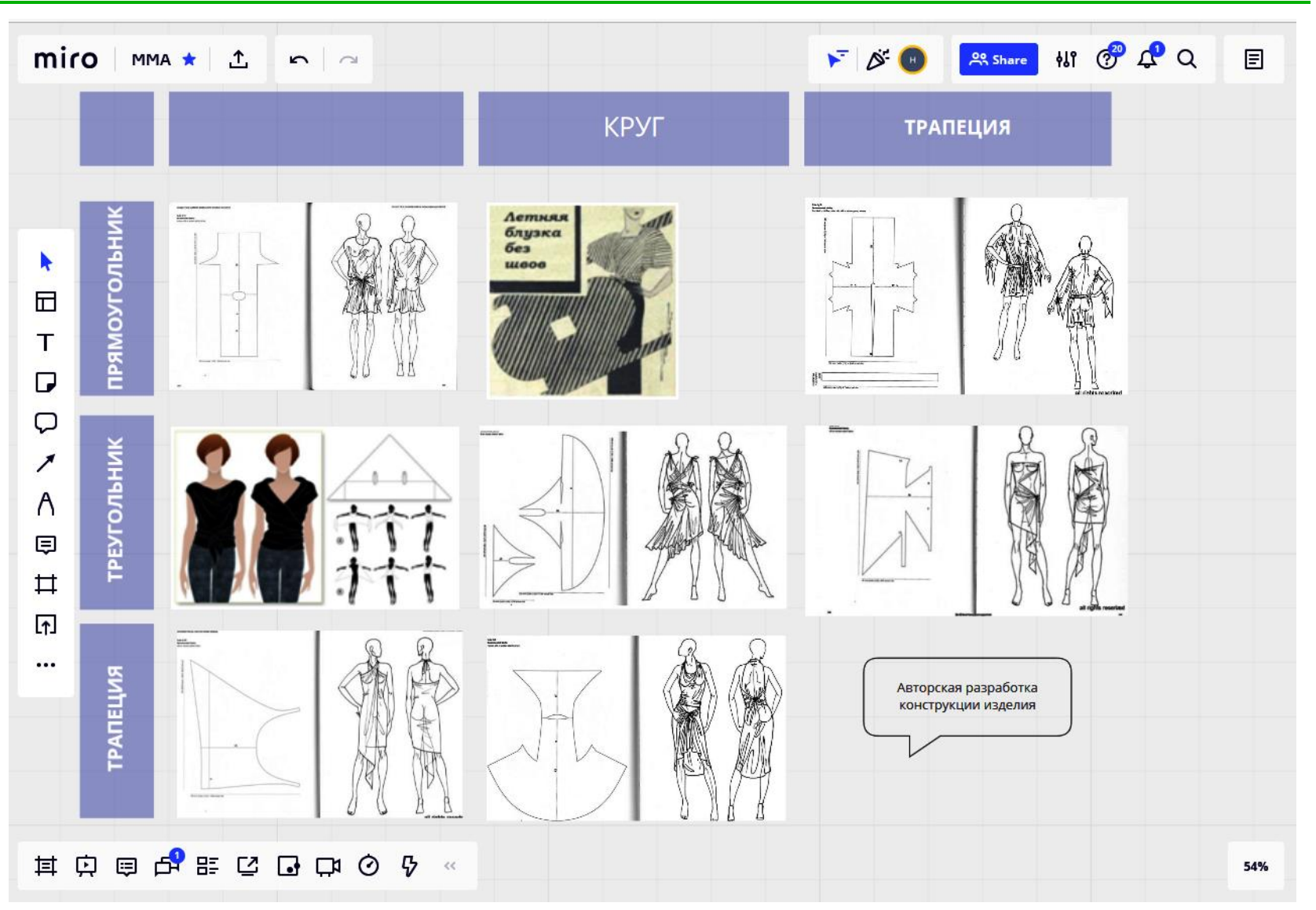

\section{Рис. 2. Морфологическая матрица моделей}

Соблюдая основной принцип разработки конструкции изделий из геометрических фигур и их комбинаций, представленных на Рис.2, на пример была получена конструкция платья без швов Рис.1, путем геометрических преобразований плоскости из равнобедренной трапеции, симметрично отображенной дважды относительно меньшего основания и один раз относительно большего. При этом линия симметрии меньших оснований была продолжена поясом, а по линии симметрии большего основания сделан вырез для горловины.

После построения основы конструкции платья, было выполнено изготовление изделия из флизилиновой ткани и проведена примерка на манекене с целью проверки соответствия конструкции фигуре. 


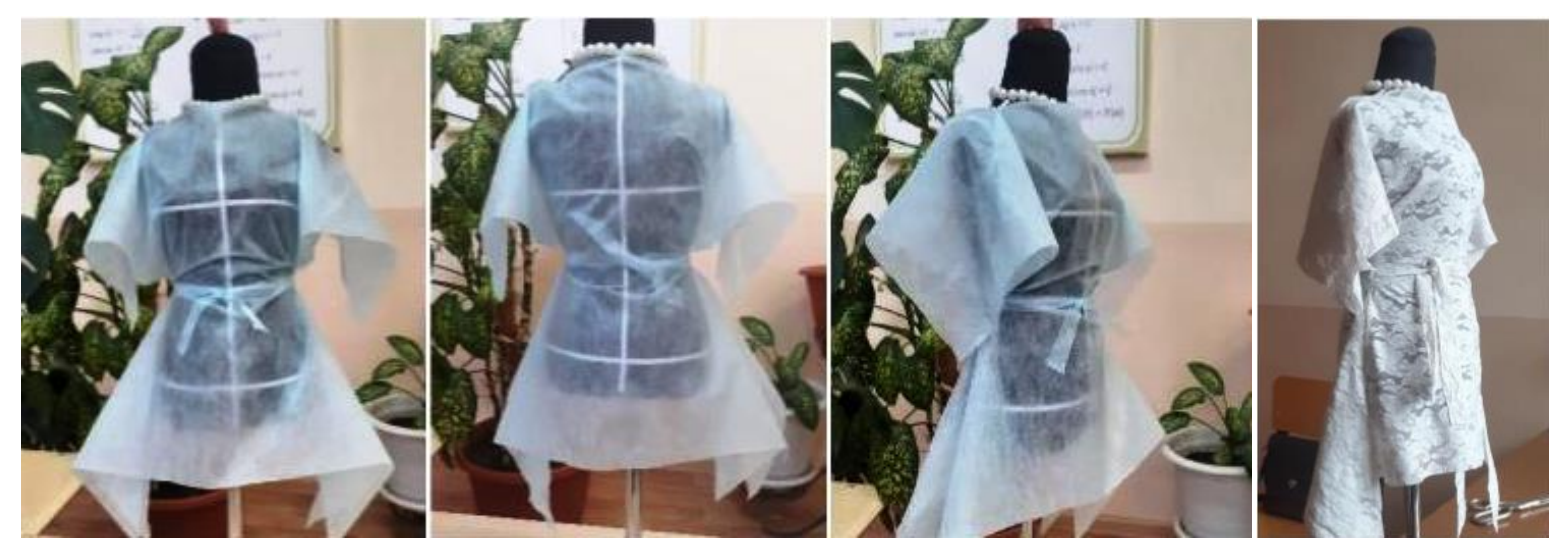

Рис. 3. Авторская модель « Платье»

Таким образом, групповая работа с морфологическими матрицами, способствовала разнообразию авторских моделей. Проводился анализ полученных результатов, их визуальная проверка на практичность применения, обсуждались способы улучшения модели, такая групповая работа усиливает генерацию идей [2, с. 217]. В процессе обмена знаниями, выслушивая ответы и предложения, каждый активизирует свою мыслительную деятельность, включается и вносит свой вклад в решение поставленной задачи, подхватывает и додумывает идеи других обучающихся что, безусловно, влияет на получение эффектного решения и развитие творческих способностей. Таким образом, морфологическая матрица может быть продолжена, с добавлением в нее всех возможных геометрических фигур и поверхностей, в сочетании которых будут получаться еще более интересные вещи [3, с. 218].

Организацию проектной деятельности делает очень наглядной, интересной, совместной интерактивной работой применение онлайн-доски Miro. Обучение работе с использование онлайн-доски проходит быстро, сервис имеет интуитивно понятную панель инструментов, чат и комментарии. Все таблицы представленные группами образуют многомерную морфологическую матрицу, которую наглядно представить помогает конструктор ментальных карт. 


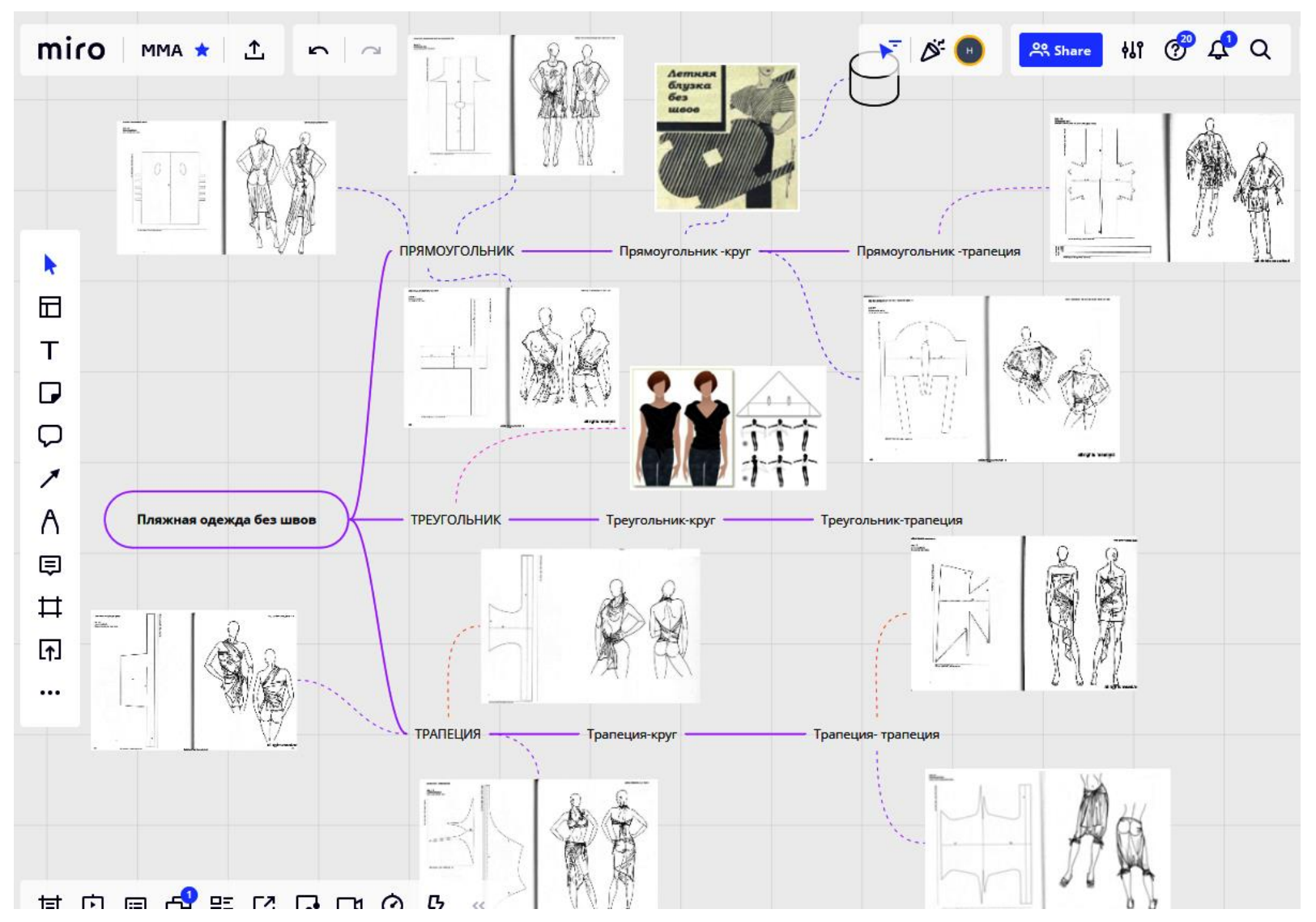

Рис. 4. Ментальная карта

Изучение видов тканей и их свойств - это увлекательная работа с каталогом в различных интернет - магазинах, заканчивается ярким морфологическим анализом. В сочетании с разрабатываемой моделью комбинаторными методами, может получиться от девяти и более вариантов видовых и цветовых решений и только некоторые из них могут иметь хорошие эргономические показатели.

Таблица 1

Анализ ткани для изделия

\begin{tabular}{|c|c|c|c|}
\hline Ткань & Трикотаж & Джинса & Лён \\
\hline Однотонная ткань & & & \\
\hline Печатный рисунок & & & \\
\hline $\begin{array}{c}\text { Направленный печатный } \\
\text { рисунок }\end{array}$ & 5乡 & & \\
\hline
\end{tabular}


В отличие от метода проб и ошибок, метод многомерных матриц позволяет получить много новых, неожиданных идей, но все, же является трудоемким процессом, в связи с этим затрудняется выбор оптимального решения. Морфологический анализ - это метод систематизации и перебора всех теоретически возможных вариантов решений. Планомерная работа с морфо таблицами развивает у обучающихся творческое воображение, дает представление о мире, как о бесконечном сочетании различных элементов, которыми можно управлять.

Проектная деятельность хорошо интегрирует знания основных понятий комбинаторики, геометрии, геометрических преобразований плоскости и начальных сведений о профессиональной деятельности такого предмета, как «Введение в специальность».

\section{Список литературы}

1. Склярова Е.Е. Организация НИРС в условиях перехода на ФГОС СПО. // Приложение СПО. - 2013. - № 4. - С. 7-14.

2. Панина Т.С. Современные способы активизации обучения: учеб.пособие для студ.высш.учеб.за-ведений / Т.С. Панина, Л.Н. Вавилова; под ред. Т.С. Паниной. - 4-е изд., стер. - М.: Издательский центр «Академия», 2008.- $176 \mathrm{c}$.

3. Кукалев С.В. Правила творческого мышления, или тайные пружины ТРИЗ: учебное пособие/ С.В. Кукалев. - М.: ФОРУМ: ИНФРА-М, 2014. -416 с. 